\title{
Visions about a Renewable Future
}

\author{
Dr. habil Bai Attila* \\ Faculty of Economics and Business, University of Debrecen, Hungary
}

Received March 31, 2016; Published April 5, 2016

Motto: "It is better to light a candle than curse the darkness." (Chinese wisdom)

The publication of the new issue of our journal coincides with Easter, the biggest Christian celebration, which is about our trust in the future and the self-sacrificing work performed to achieve this future, as well as renewal. The future of Earth is shaped by the current youth, while that of energetics is shaped by renewables. For this reason, one of the main objectives of our journal is to help young researchers with high-ranking publication opportunities and high-standard knowledge about the future's energy. Therefore, it is a great feeling to dip into the fourth issue and to thank those who contributed either as editors, authors, reviewers or readers. I would like to strongly encourage anyone who is thinking about joining us in the future.

Despite the energy saving measures currently in force, the increase of living standards calls for increasing amount of energy which appears mainly in developing countries. However, the energy consumption of the world increased only by $0.5 \%$ in 2014 (to $575 \mathrm{EJ}$ ) in comparison with the previous year which was significantly exceeded by the increase of GDP (2.9\% per year); therefore, specific energy consumption became much more efficient. At the same time, the difference of the spatial structure of production and use, the environmental protection issues caused by fossil energy resources and the fact that their extraction cannot be increased even in the mid-term pose serious problems. For this reason, sustainable development can only take place with the increased use of renewable energy which calls for the use of different procedures, technologies, and plant size in each country. In 2015, around 329 billion USD was invested into energy projects, but, according to IMF World Economic Outlook Update 2016 [1], in order to make the energy sector environmental friendly, at least 16,500 billion USD would need to be invested globally of the 68,000 billion USD which the countries of the world planned to invest into the energy industry until 2040 anyway [1]. Policymakers decide about sums, strategic and geopolitical interests which are almost impossible to comprehend. However, we, researchers, voters, and energy consumers are also able to make positive influences which we would like to do also with our journal by publishing new findings, objective data and conclusions.

It is obvious that there will probably never be any energy resource that is cheap, energy-friendly, does not endanger the interests of any economic sector, has infinite 
feedstock basis and end product market, while creating lots of new employment possibilities at the same time. For this reason, it is difficult to estimate which renewable energetic procedure will become widespread, as well as to what extent and how quickly.

The main feedstock of heat production - which is the cheapest and most widely used type of energy - will probably remain biomass in the future. Based on the currently prevailing forestry products - in order to guarantee the saving of arable land -, the significance of special energy plantations and by-products is expected to increase. The latter can mostly be used for local purposes which will result in the possibility of reducing energetic and transport losses.

In the mid-term, China is expected to use solar and water energy, Western Europe will use wind energy and the United States will use solar energy for electricity production purposes. The utilisation of waste heat produced by power plants can play an important role in the development of local communities (job creation, local taxes) in addition to energy efficiency by means of attracting heat energy-demanding industries.

In the fuel market, the spreading of next generation biofuels is expected to replace the economically and energetically most problematic first generation biodiesel within some years, as well as maize-based and eventually (in the long run) even sugar cane-based bioethanol production. As a consequence, the price of timber industry products and crop production byproducts will increase, as well as the price of feed as a result of disappearing first generation fuel by-products and there will be a notable increase of proportion of energy plantations in the field crop rotation. The advantage of the latter phenomenon could be the involvement of less favourable arable land into production, while a potential disadvantage is intensifying deforestation.

In my opinion, the only potential successful procedures are the ones which are able to solve waste- and carbon dioxide disposal at the same time in addition to energy production, the ones which can be operated in a closed systems (with no waste generation) and are able to produce various types of end products. Of these, the most promising alternatives may be the animal feed- or biodiesel-focused utilisation of algae species, produced with simplified (cheaper) PBR technologies, using flue gases and waste heat produced in wastewater-based biogas plants (or fossil power plants) - from the aspects of environmental protection, economics and novelty content. Furthermore, at the consumer level, I think that local public transport (buses) could be the first step of a wider range of using biofuels, since it would provide a possibility to use a significant amount of biofuel for masses of lower income people especially in city traffic, where pollutant emission appears in a concentrated amount and refuelling can be smoothly performed even if no countrywide fuel station system is established.

While oil contributed to the enrichment of Arab countries half a century ago, I think that the need for higher biomass productivity and sustainability in the future will primarily result in the flourishing of capital export to tropical countries.

As a matter of course, these are only general remarks and problems and looking for a solution always takes a specific set of circumstances. This is why we established our journal. Feel free to send us your manuscripts, opinions and suggestions and, if you think 
our published papers deserve it, please recommend them to your acquaintances and cite us!

\section{REFERENCES}

[1] International Monetary Fund (2016) World Economic Outlook (WEO) Update, http://www.imf.org/external/pubs/ft/weo/2016/update/01/pdf/0116.pdf (accessed on 04/02/2016)

Article copyright: $(\underset{0}{2016}$ habil Bai Attila. This is an open access article distributed under the terms of the Creative Commons Attribution 4.0 International License, which permits unrestricted use and distribution provided the original author and source are credited. 